\title{
Jogos de estafetas desenvolvimentistas cognitivos
}

\section{Cognitive developmental relay games}

\section{Ricardo Fodrigo Rech}

Universidade de Caxias do Sul (UCS)

Liga Acadêmica em Educação Física Escolar

E-mail: rrrech@ucs.br

\section{Gerard Maurício Martins Fonseca}

Universidade de Caxias do Sul (UCS)

Liga Acadêmica em Educação Física Escolar

E-mail:gmmfonse@ucs.br

\section{RESUMO}

O modelo pedagógico para o ensino da educação física conhecido como Abordagem Desenvolvimentista tem na sua base teórica o enfoque na aquisição de habilidades motoras. Os jogos de estafetas são brincadeiras com base em corridas, onde cada participante deve percorrer um trajeto delimitado procurando realizá-lo no menor tempo possível. A proposta que segue, apresenta os Jogos de Estafetas Desenvolvimentistas Cognitivos. Quando conseguimos estabelecer conexões entre as tarefas motora e cognitiva, ampliando gradualmente a complexidade da atividade, estaremos contribuindo para o desenvolvimento de novas conexões neurais e estimulando a plasticidade cerebral. Os referidos jogos vêm sendo trabalhados com êxito por professores de Educação Física que atuam nas redes pública e privada de ensino da cidade de Caxias do Sul, sendo boas opções para as aulas de educação física na educação básica.

Palavras-chave: educação física, desenvolvimentista, cognitivo 


\section{ABSTRACT}

The pedagogical model for teaching physical education known as the Developmental Approach has in its theoretical basis the focus on the acquisition of motor skills. The relay games are games based on races, where each participant must run a defined path trying to accomplish it in the shortest time possible. The following proposal presents the Cognitive Developmental Relay Games. When we can establish connections between motor and cognitive tasks, gradually increasing the complexity of the activity, we will be contributing to the development of new neural connections and stimulating brain plasticity. These games have been successfully used by physical education teachers in public and private schools in the city of Caxias do Sul, and are good options for physical education classes in basic education.

Keywords: physical education, developmental, cognitive

\section{SOBRE A ABORDAGEM DESENVOLVIMENTISTA}

O modelo pedagógico para o ensino da educação física conhecido como Abordagem Desenvolvimentista tem na sua base teórica o enfoque na aquisição de habilidades motoras. Esta abordagem pedagógica está ancorada nos princípios do desenvolvimento motor, que é um processo contínuo e demorado, sendo que as principais alterações ocorrem nos primeiros anos de vida. Assim sendo, no ambiente educacional ela é dirigida para crianças e jovens que estudam essencialmente no ensino fundamental (4 aos 14 anos). Para Gallahue e Donnelly (2008) o principal objetivo da Educação Física é proporcionar vivências e experiências de movimento adequadas ao nível de crescimento e desenvolvimento das crianças e jovens, a fim de que a aprendizagem das habilidades motoras seja obtida. A criança deve ser confrontada com desafios motores variados, por meio de atividades, brincadeiras e jogos, proporcionando 0 desenvolvimento de seu repertório motor e melhorando a ação diária do aluno. Segundo os autores, os estudantes devem aprender a mover-se (domínio motor) e aprender através do movimento (aprendizagem cognitiva e afetiva). Neste artigo focaremos apenas nos aspectos motores e cognitivos dos jogos que serão apresentados, apesar do domínio afetivo estar presente em todas as atividades. 
Em relação ao domínio motor, os movimentos corporais estão categorizados em estabilizadores, locomotores e manipulativos, sendo eles o foco principal das atividades. No que diz respeito a aprendizagem cognitiva, ela pode ser conceituada como o processo pelo qual a informação é organizada, colocada na memória e posta a disposição para ser relembrada e aplicada a uma variedade de situações. Este conceito oferece aos estudantes as ferramentas para um pensamento crítico, onde eles utilizam as atividades de movimento para auxiliar na retenção, recordação, tomada de decisão e aplicação (GALLAHUE; DONNELLY, 2008).

De acordo com Tavares e Casanova (2013) o indivíduo "expert" na resolução de problemas motores é capaz de assimilar as informações mais importantes envolvidas na situação (jogos, lutas, brincadeiras) e formar instantaneamente pelo uso da atenção seletiva e memória, um modelo que possibilite a tomada de decisão mais favorável e rápida para o momento. Por isto é necessário estimular os processos perceptivo-cognitivos que desempenham um papel importante na tomada de decisão.

O processo perceptivo-cognitivo é um componente do processamento da informação que é ativado quando surgem os estímulos proporcionados pelo meio externo ou pelo próprio corpo e que são captados pelos órgãos dos sentidos (sensação). Na sequência, eles são selecionados, organizados e interpretados (percepção), ganhando um significado como informação. Estas informações determinam uma seleção da resposta (tomada de decisão), que definirá uma ação a ser feita. A partir da seleção da resposta, define-se o caminho/sequência (efetor) para a construção do programa motor que organizará o movimento por meio do sistema osteomuscular, realizando assim o movimento (resposta) (RINK, 2010; SCHIMIDT e WRISBERG, 2000; SICILIA et al 1999).

\section{SOBRE OS JOGOS DE ESTAFETAS}

Os jogos de estafetas são brincadeiras com base em corridas, onde cada participante deve percorrer um trajeto delimitado procurando realizá-lo no menor tempo possível. De acordo com Fonseca e Silva (2011) os jogos de estafetas pertencem a categoria dos jogos recreativos, sendo possível sua utilização em vários conteúdos das aulas de educação física escolar. A quantidade de equipes 
para participar dos jogos dependerá dos objetivos da aula, do tamanho da turma e dos materiais que temos a disposição na escola. Entretanto é importante lembrar que quanto menor o tamanho das equipes (componentes), maior a participação individual de cada aluno e por consequência, menor o tempo de ócio. Da mesma forma, o professor não deve esquecer que as crianças possuem estágios de aprendizagem diferentes, por isto, equilibrar as equipes em relação ao seu desenvolvimento motor e cognitivo também é um ponto que merece atenção, para que os jogos se tornem mais interessantes. (LAEFIE, 2020)

Os Jogos de Estafetas podem ser divididos em dois tipos:

- Estafetas de Revezamento: quando cada componente do grupo realiza o trajeto de forma individual, revendo com o colega seguinte ao final do seu percurso.

- Estafeta Cooperativa: quando a equipe toda ou parte dela realiza o trajeto juntos.

Para Fonseca e Silva (2011) os jogos de estafeta são de fácil aplicação no ambiente escolar, apresentando aspectos relevantes na sua prática. Abaixo são apresentados alguns pontos que não podem passar despercebidos pelo professor no momento de sua escolha como estratégia de ensino:

- as regras são simples e claras e possibilitam a adaptação de diversos materiais para sua execução;

- a possibilidade de que os alunos participem em igualdade de condições, já que todos devem realizam as mesmas habilidades motoras dentro de um contexto motivacional do jogo;

- o professor poderá montar um trajeto que atenda aos objetivos e conteúdos que ele esteja desenvolvendo nas suas aulas, aumentando ou não o tempo de execução e a dificuldade e complexidade das tarefas;

- como os jogos de estafetas são atividades que criam condicionantes de pressão coordenativa de tempo (fazer rápido) o executante pode preocupar-se mais em "chegar na frente" do que realizar a tarefa adequadamente podendo não atender ao objetivo da atividade;

Um inconveniente dos jogos de estafetas tradicionais reside no fato de que eles pouco estimulam aspectos cognitivos, pois sua estratégia (tática) básica é fazer mais rápido a tarefa do percurso. Todavia, quando adaptamos estes aos 
preceitos da abordagem desenvolvimentista, podemos minimizar ou eliminar este aspecto mais frágil, transformando estes em Jogos de Estafetas Desenvolvimentistas Cognitivos.

\section{OS JOGOS DE ESTAFETAS DESENVOLVIMENTISTAS COGNITIVOS}

Como já discutimos no início deste texto, a abordagem desenvolvimentista defende a ideia de que o movimento corporal é a linha mestra no desenvolvimento de habilidades com características estabilizadoras, locomotoras e manipulativas. O desenvolvimento destes movimentos corporais é o principal meio e fim da Educação Física, principalmente no ambiente escolar. Assim sendo, da prática das habilidades motoras ocorrerá o aumento do repertório motor e indiretamente o desenvolvimento de aspectos perceptivo motores como atenção, memória, tomada de decisão, organização espacial e temporal, principalmente quando o conteúdo dos jogos e brincadeiras estimularem isto (RECH e FONSECA, 2019).

Desta forma, o desafio que se apresenta na aula com enfoque na abordagem desenvolvimentista é construir estratégias que envolvam o desenvolvimento do repertório motor e ao mesmo tempo estimulem o desenvolvimento da capacidade perceptiva e cognitiva do aluno. Para isto os Jogos de Estafetas Desenvolvimentistas Cognitivos, como uma das estratégias de ensino, permitem que o professor desenvolva as habilidades estabilizadoras, locomotoras e manipulativas no momento da realização do trajeto, associado ao enfrentamento de situações com características cognitivas.

Por exemplo, num jogo de estafeta tradicional, a criança percorre um trajeto até um ponto e retorna para trocar com o colega. Por sua vez, num Jogo de Estafeta Desenvolvimentista Cognitivo, durante o trajeto que o estudante tem que percorrer ele realiza habilidades com enfoque nas categorias dos movimentos (estabilização, locomoção e manipulação), e ao chegar ao final resolve algum tipo de problema que estimule o desenvolvimento dos aspectos cognitivos. Desta forma, quando o professor estabelece conexões entre as tarefas motora e cognitiva, ampliando gradualmente a complexidade da atividade, estará contribuindo para o desenvolvimento de novas conexões neurais, estimulando a plasticidade cerebral, a tomada de decisão, além de aspectos de organização espacial e temporal, estes últimos sempre presentes nas atividades de 
movimento.

A seguir são apresentados 4 Jogos de Estafetas Desenvolvimentistas Cognitivos. As atividades serão descritas brevemente e cabe ressaltar mais uma vez que cada professor pode e deve adaptar as atividades de acordo com seu objetivo, espaço e material disponível (LAEFIE, 2020). Apenas a descrição do jogo cognitivo será abordada. No que diz respeito ao trajeto (percurso), cabe ao professor adaptar conforme seus objetivos motores de aula.

4 JOGO 1 - Jogo da Memória (tradicional) - Dividir a turma em equipes e posicionar ao final do percurso as peças do jogo de memória. As peças podem ser penduradas em uma rede ou colocadas sobre classes. Podem ser peças já prontas ou confeccionadas com temas específicos da educação física (esportes, materiais, anatomia). Ao chegar nas peças o participante deve virar duas delas, se formar a dupla, deve deixá-las com a imagem para cima, se não formar a dupla deve deixá-las na posição inicial.

4.1 Observações importantes: Conforme o material do jogo (TNT por exemplo), ele pode ser pendurado por prendedores em uma rede ou cerca estimulando a execução de habilidades motoras finais na manipulação. Outro aspecto importante é posicionar as peças de acordo com o nível dos alunos. Por exemplo, para a educação infantil, usar menos peças e colocá-las em forma de linhas e colunas, facilitando a noção espacial.

Figura 1 - Jogo da Memória Tradicional

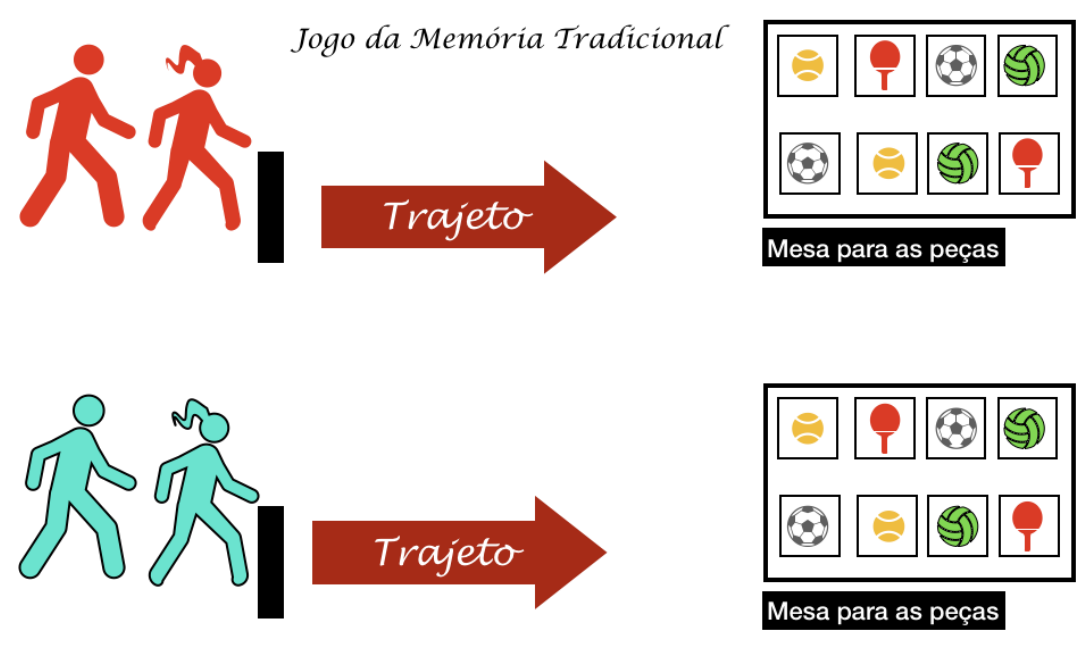

4.2 JOGO 2 - Jogo da Velha gigante: Montar ao final do percurso das equipes 
uma estrutura com bambolês, formando um quadrado com no mínimo com seis bambolês em cada linha (36 bambolês). Montar a estrutura para cada duas equipes. Cada equipe deverá ter 20 chinesinhos da mesma cor. Um estudante de cada vez deve levar o chinesinho até a estrutura e colocá-lo dentro de um bambolê e voltar, revezando com seu colega de equipe. O objetivo é formar linhas (longitudinais, transversais e diagonais) com três chinesinhos seguidos, como no jogo da velha tradicional. Quando toda a estrutura estiver preenchida, termina o jogo. Ao final as equipes devem se reunir ao lado da estrutura e analisar as melhores opções para retirar as peças, pois devem retirar os chinesinhos de três em três, considerando a melhor opção para marcar pontos. Uma equipe por vez deve retirar as peças. Cada linha feita com 3 peças vale um ponto.

4.3 Observação importante: a utilização de bambolês na montagem da estrutura é mais fácil e rápida, porém eles ocupam muito espaço, além de necessidade de grande quantidade para cada estrutura. Por isto, a montagem da grade pode ser feita com giz ou fita crepe.

Figura 2 - Jogo da Velha Gigante

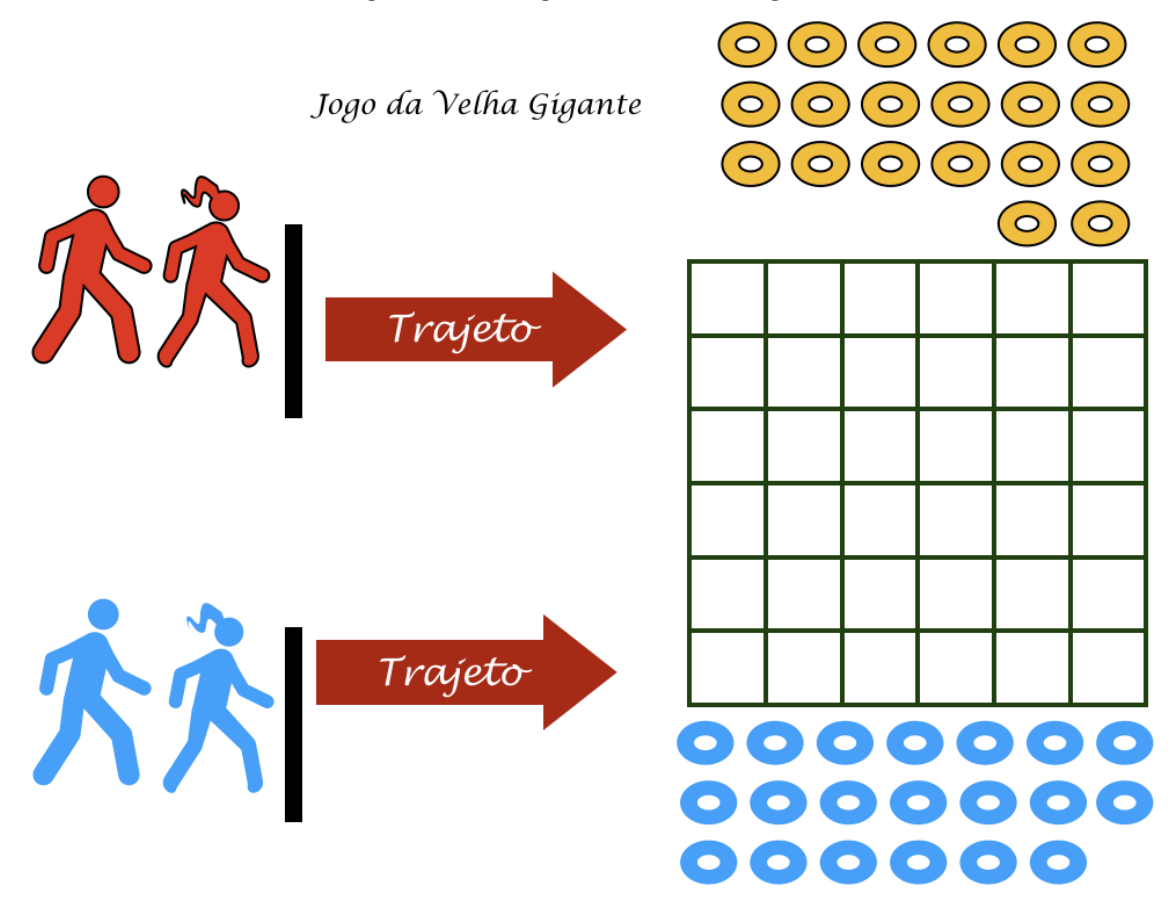

4.6 JOGO 3 - Candy Crush Invertid o: Dividir a turma em equipes de acordo com a quantidade de material. Montar ao final do percurso de cada equipe uma grade 
com fita crepe de 3 linhas e 8 colunas. Na frente colocar 24 chinesinhos (três cores diferentes) no chão. $O$ aluno deve ir até a estrutura e colocar um chinesinho de cada vez, dentro de um quadrado mantendo as três cores diferentes na mesma linha horizontal e não podendo repetir a mesma cor em sequência com a linha vertical. Cada jogador só pode colocar um chinesinho por vez.

4.7 Observação importante: Para construir a grade (gabarito) o professor pode utilizar giz ou cordas. Na falta de material suficiente, o professor pode utilizar materiais diferentes para cada equipe. Por exemplo, chinesinhos, tampas de garrafas pet, pedras, etc.

Figura 3 - Candy Crush Invertido

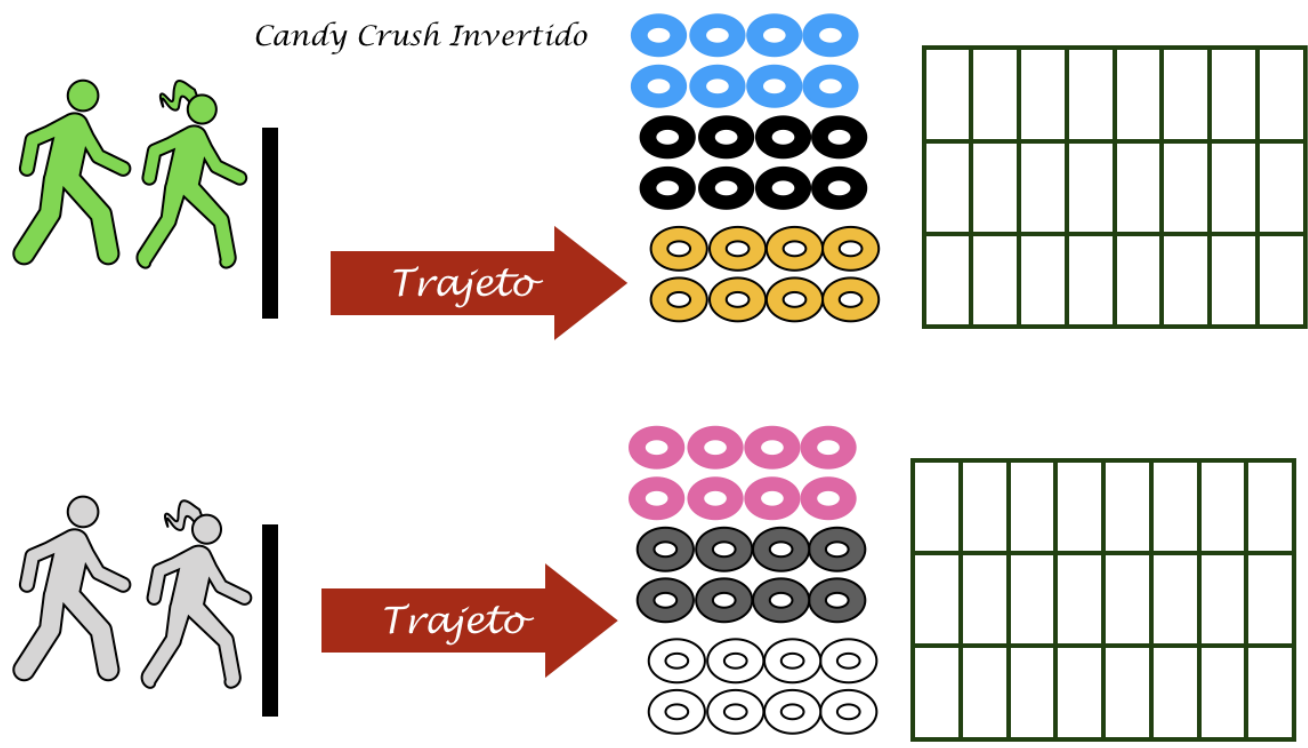

4.8 JOGO 4 - Jogo do Antecessor: o participante deve realizar a tarefa do percurso, se dirigir até o tabuleiro, lançar os dados para cima e verificar quais números caíram virados para cima. Por exemplo: se um dado caiu com o número 3 e o outro caiu com o número 4 virados para cima, $3+4=7$. Quando a soma for igual a 7, o participante deve colocar o objeto (pedrinha, tampinha) no número que ANTECEDE o número 7 , que neste caso é o número 6 . O tabuleiro deve variar entre 1 e 11. O grupo que encontrar primeiro 6 antecessores diferentes vence a partida. Se por acaso o número for repetido, o participante deve lançar os dados para cima novamente (no máximo 2 lançamentos por jogador). 
Figura 5 - Jogo do Antecessor
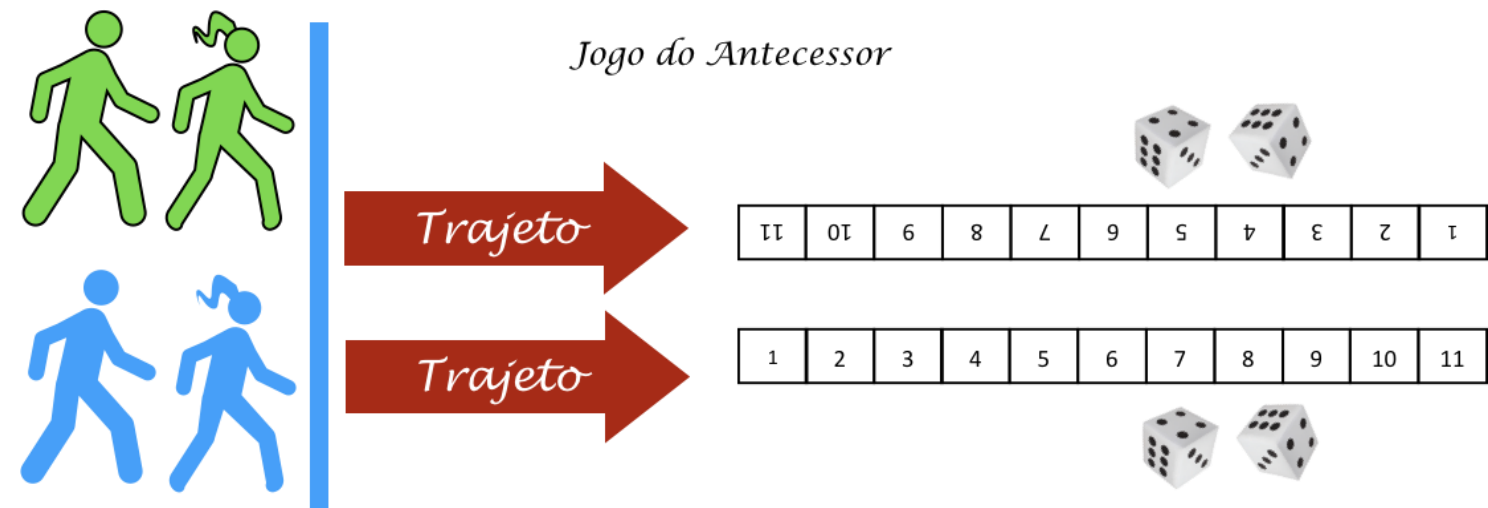

\section{CONSIDERAÇÕES FINAIS}

A ênfase na descrição e proposição das atividades nos jogos de estafetas desenvolvimentistas cognitivos foi no aspecto cognitivo. Porém não podemos esquecer que a abordagem desenvolvimentista está centrada nas três categorias de movimentos (estabilizadores, locomotores e manipulativos), desta forma 0 trajeto/percurso deve estar em consonância com estas habilidades.

Da mesma forma, como já destacado anteriormente, caberá ao professor definir e adaptar materiais para a atividade e nível de complexidade dos jogos de acordo com o estágio de aprendizagem dos seus alunos.

Cabe ressaltar ainda que o professor precisa levar em conta o equilíbrio na formação das equipes para que o jogo fique mais atraente. Este equilíbrio deve considerar aspectos de desenvolvimento motor e cognitivo. Também é importante que o professor divida a turma no maior número possível de equipes para dar dinamismo a atividade e evitar que os alunos fiquem muito tempo sem participar.

Para finalizar vale lembrar que professor não deve esquecer de considerar o tempo demandado para montar e desmontar a estrutura das atividades, não incorrendo assim na perda de muito tempo de sua aula. Consideramos os jogos de estafetas desenvolvimentistas cognitivos uma boa opção para as aulas de educação física, cabendo ao professor definir o momento de inseri-los em seu planejamento. 


\section{REFERÊNCIAS}

GALLAHUE, David L.; DONNELLY, Frances Cleland. Educação física desenvolvimentista para todas as crianças. 4. ed. São Paulo: Phorte, 2008.

FONSECA, Gerard Maurício Martins; SILVA, Mauro Amancio. Jogos de futsal: da aprendizagem ao treinamento. 2. ed. Caxias do Sul: EDUCS, 2011.

LIGA ACADÊMICA EM EDUCAÇÃO FÍSICA ESCOLAR (LAEFIE). Educação física escolar desenvolvimentista: propostas de atividades com materiais diversos. Caxias do Sul: EDUCS, 2020.

RECH, Ricardo Rodrigo; FONSECA, Gerard Maurício Martins. Educação Física Escolar: propostas pedagógicas para a educação básica. Caxias do Sul: São Miguel, 2019.

RINK, Judith. Teaching Physical Education for learning. 6를 ed. New York: McGrawHill, 2010.

TAVARES, Fernando; CASANOVA, Filipe. A atividade decisional do jogador nos jogos desportivos coletivos. (p: 55-73) In: TAVARES, Fernando. (ed). Jogos Desportivos colectivos: ensinar a jogar. Porto: FADEUP, 2013.

SCHMIDT, Richard; WRISBERG, Craig. Aprendizagem e Performance Humana. Porto Alegre: Artmed, 2000.

SICILIA, Antonio; MARIN, Manuel; HERNÁNDEZ, Francisco; PÉREZ, Luis. Control y Aprendizaje Motor. Madrid: Sintesis, 1999. 